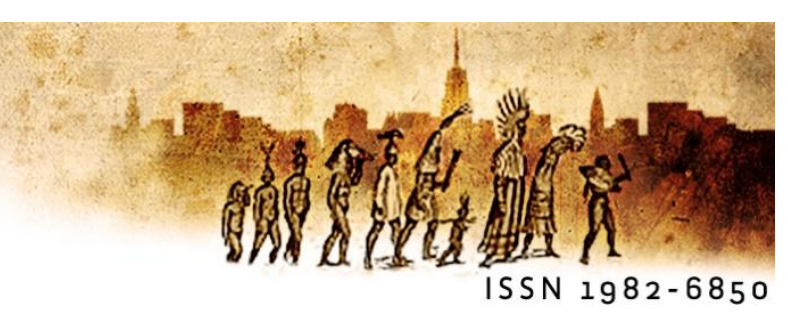

\title{
A gramática nas escolas hoje: como agem e como pensam os professores
}

\author{
Maria Claudete Lima' (UFC) \\ Camila Stephane Cardoso Sousaii (UFC) \\ Ana Célia Clementino Mouraiii (UFC)
}

\section{Resumo:}

Há mais de vinte anos, os documentos oficiais recomendam um ensino de gramática contextualizada (BRASIL, 1998; BRASIL, 2000; BRASIL, 2018). Data do mesmo período a infinidade de trabalhos que discutem a questão do ensino de língua portuguesa e de gramática (POSSENTI, 1996; TRAVAGLIA, 1996; NEVES, 1990; 2003; VIEIRA, S.R.; BRANDÃO, S.F., 2007). Recentemente, a Base Nacional Comum Curricular acrescentou ao nome "análise linguística" - como passou a ser chamado o ensino de gramática nos Parâmetros Curriculares Nacionais, para destacar a necessidade de se partir do texto - o nome "semiótica", para abranger a análise de textos multimodais. Nosso objetivo neste trabalho é mostrar que, apesar do avanço nas pesquisas e das recomendações nos documentos oficiais, a prática do ensino de gramática nas escolas ainda não alcança a desejada integração texto e gramática. Para tanto, analisamos quali-quantitativamente, com base em Neves (2002), as respostas a um questionário com perguntas abertas e fechadas aplicado a 171 sujeitos, 88 professores de língua portuguesa ainda em formação e 83 professores em atividade. Os resultados mostram que, embora reconheçam teoricamente a validade de uma gramática atrelada aos textos, os professores em formação e em atividade têm dificuldade em aplicar os conhecimentos de linguística e as recomendações oficiais na prática do ensino de gramática. Tal resultado indicia que os cursos de formação de professores de língua precisam enfrentar esta questão, seja reformulando a grade para incluir disciplinas que deem conta de um ensino produtivo para além das disciplinas teóricas, seja inserindo, nas disciplinas já existentes unidades de aplicação dos conteúdos teóricos.

Palavras-chave: Ensino de gramática. Formação de professores. Base Nacional Comum Curricular.

\footnotetext{
Abstract:

For more than twenty years, the official documents recommend a contextualized grammar teaching (BRAZIL, 1998, BRAZIL, 2000, BRAZIL,
} 
2018). Around the same period the infinity of works that discuss the topic of Portuguese language and grammar teaching were written (POSSENTI, 1996; TRAVAGLIA, 1996; NEVES, 1990; 2003; VIEIRA, S.R; BRANDÃO, S.F., 2007). Recently, the Plan National Curricular added to its name "linguistic analysis", as, from this point forward, it was called to teach grammar in the National Curricular Parameters, to highlight the necessity of having the text as a starting point, the name "semiotics", to cover the analysis of multimodal texts. Our goal on this work is to show that, despite the advance of the researches and the recommendations in the official documents, the actual practice of teaching grammar in school still doesn't achieve the desired integration of text and grammar. To do so, we analyzed qualitatively and quantitatively, having as base Neves (2003), the answers to a survey with essay questions and multiple choice questions applied to 171 individuals, 88 teachers of Portuguese language that are still in formation and 83 that are already in full activity. The results show that, although they theoretically recognize the value of a grammar attached to the text, the teachers that are still in formation and the teachers that are already in full activity face difficulties in applying linguistic knowledge and official recommendations on the actual practice of teaching grammar. This result suggests that the training courses for language teachers need to face this issue, either by adding disciplines that account for productive teaching, so besides the theoretical disciplines, either by inserting units of application of theoretical content.

Keywords: Grammar teaching. Teacher training. National Curricular Common Base.

\section{Introdução}

O ensino de gramática é tema desgastado na comunidade acadêmica. Já muito se escreveu sobre o problema de uma prática de ensino de gramática voltada apenas para a nomenclatura ou regras descontextualizadas (POSSENTI, 1996; TRAVAGLIA, 1996; NEVES, 1990; 2003; VIEIRA, S.R.; BRANDÃO, S.F., 2007; DUTRA; RÉGIS, 2017). Há mais de vinte anos, os documentos oficiais recomendam um ensino de gramática pautado no texto (BRASIL, 1998; BRASIL, 2006; BRASIL, 2017).

A questão que ecoa hoje é se tanta insistência oficial, tanta pesquisa e tanta produção na área terão repercutido nas formações de professores e, principalmente, em suas práticas. Ou seja, até que ponto essa ampla discussão em torno do ensino de gramática trouxe resultados no ensino de língua que nossos professores ministram nas escolas do ensino fundamental e médio?

Tal problema é discutido por Alves (2017) que analisa avaliações do $7^{\circ}$ e $8^{\circ}$ ano do Ensino Fundamental, aplicadas em 2015, a fim de detectar pistas de como anda o ensino de gramática nas escolas, e conclui que "nas duas avaliações analisadas todas as questões de gramática foram de natureza de categorização e classificação" (ALVES, 2017, p.302). 
Chega a resultado semelhante a pesquisa de Araújo, Sousa Filho e Lima (2018), que analisa as concepções de linguagem que norteiam a prática de ensino de gramática/análise linguística por professores do ensino médio. Os autores entrevistam e aplicam questionário a quatro professores, durante os anos 2016 e 2017 e concluem que "embora instituída como eixo de ensino, [a análise linguística] não foi abordada na mesma proporção que os eixos de leitura e escrita, ainda vigorando o estudo do componente linguístico à luz da norma e/ou da descrição estrutural, sem estabelecer uma relação com o plano textual enunciativo" (ARAÚJO, SOUSA FILHO; LIMA, 2018, p. 288).

Nos livros didáticos, a situação não parece ser diferente, como pondera Nascimento (2018), que avaliou se os livros didáticos seguem as recomendações dos PCN. Para tanto, a autora analisou um livro didático de 1975, anterior ao documento, e outro livro, distribuído nas escolas públicas, publicado em 1998 e 2014. A conclusão é que "poucas foram as mudanças ocorridas no ensino de gramática após a implementação dos Parâmetros Curriculares Nacionais (PCN), prevalecendo, ainda, um estudo tradicional em detrimento de uma análise reflexiva da língua em uso" (NASCIMENTO, 2018, p. 4).

Tais resultados apontam para a manutenção de práticas anteriores aos documentos oficiais e às pesquisas no ensino de gramática nas escolas. Todavia, essas pesquisas, embora representem boa contribuição para o conhecimento do ensino da gramática na contemporaneidade, são limitadas, como reconhecem, pelo tamanho da amostra. Em Alves (2017), foram analisadas apenas duas avaliações. Em Araújo, Sousa Filho e Lima (2018) foram ouvidos quatro professores. Em Nascimento (2018), foram analisados dois livros didáticos.

Nosso objetivo no presente artigo é ampliar essa discussão, averiguando se, passadas duas décadas, a prática do ensino de gramática nas escolas alcançou a desejada integração texto/gramática. Para tanto, analisamos quali-quantitativamente, com base em Neves (2003), as respostas a um questionário com afirmações sobre ensino de gramática e avaliação de questões de gramática com escala Likert de 5 pontos, que foi aplicado a 171 sujeitos, 88 professores de língua portuguesa ainda em formação e 83 em plena atividade em 2019.

Este artigo acha-se dividido em quatro partes, além desta introdução. Na próxima seção, apresentaremos brevemente as recomendações sobre ensino de gramática nos documentos oficiais. Em seguida, apresentaremos a metodologia da pesquisa realizada. $\mathrm{Na}$ 
seção seguinte, discutiremos os resultados quantitativos e analisaremos qualitativamente as respostas, dialogando com Neves (2003). Ao final, faremos uma síntese dos resultados

\section{A gramática no ensino de língua materna}

Como já ressaltamos, a literatura sobre ensino de gramática é farta no Brasil. Evitamos, nesta seção, resenhar tais trabalhos, por julgarmos o tema por demais conhecido dos leitores. Traçaremos breves linhas sobre as recomendações dos documentos oficiais, enfatizando o texto da Base Nacional Comum Curricular (BNCC), por ser mais recente, antes de nos debruçarmos sobre os dados.

A discussão sobre a necessidade de o ensino de gramática ser pautado em textos já tem pelo menos 35 anos. Como mostra da antiguidade do tema, retrocederemos a Geraldi (1984), obra que inspirou a nomenclatura "análise lingüística", "atividade epilingüística" e "atividade metalingüística" adotada nos PCN (BRASIL, 1998, p.30). Não convém, porém, entender a proposta do termo como mera mudança de nomenclatura, contra a qual se insurge o próprio Geraldi:

O uso da expressão 'análise linguística' não se deve ao mero gosto por novas terminologias.(...)

Essencialmente, a prática de análise linguística não poderá limitar-se à higienização do texto do aluno em seus aspectos gramaticais e ortográficos, limitando- -se a 'correções'. Trata-se de trabalhar com o aluno o seu texto para que ele atinja seus objetivos junto aos leitores que se destina (GERALDI,1984, p.74).

De fato, é o que propõem os PCN do ensino fundamental quando falam em atividades de análise linguística:

As atividades de análise lingüística são aquelas que tomam determinadas características da linguagem como objeto de reflexão. (...)

Isso torna possível organizar um trabalho didático de análise lingüística, aqui denominado "Análise e reflexão sobre a língua", cujo objetivo principal é melhorar a capacidade de compreensão e expressão dos alunos, em situações de comunicação tanto escrita como oral. (BRASIL, 1998, p. 48).

Trata-se, noutras palavras, de tomar texto como ponto de partida e ponto de chegada das reflexões linguísticas. Já os PCN do ensino médio não usam o termo "análise linguística". Adotam uma visão mais unificada de linguagem, relacionando a língua portuguesa com outras linguagens como a arte e o esporte. A ênfase tanto nos PCN do ensino médio, como 
nos chamados $\mathrm{PCN}+$, que dão orientações curriculares, é nas competências e habilidades a serem desenvolvidas no ensino de língua portuguesa, as quais constituem a matriz de referência do Enem. De todo modo, permanece a visão social e interativa da linguagem, como se depreende do trecho:

Os conteúdos tradicionais de ensino de língua, ou seja, nomenclatura gramatical e história da literatura, são deslocados para um segundo plano. O estudo da gramática passa a ser uma estratégia para compreensão/interpretação/produção de textos e a literatura integra-se à área de leitura. (...) A gramática extrapola em muito o conjunto de frases justapostas deslocadas do texto. O texto é único como enunciado, mas múltiplo enquanto possibilidade aberta de atribuição de significados, devendo, portanto, ser objeto também único de análise/síntese. (BRASIL, 2000, p.18-19).

Mais recentemente, o termo "análise linguística" é retomado na Base Nacional Comum Curricular - BNCC (2017), acrescido do nome semiótico:

O eixo da análise linguística/semiótica, que envolve o conhecimento sobre a língua, sobre a norma-padrão e sobre as outras semioses, que se desenvolve transversalmente aos dois eixos - leitura/escuta e produção oral, escrita e multissemiótica - e que envolve análise textual, gramatical, lexical, fonológica e das materialidades das outras semioses (BRASIL, 2017, p. 80).

A BNCC mantém ainda os eixos centrais a serem considerados de forma integrada no ensino de Língua Portuguesa, tanto no ensino fundamental como no ensino médio: leitura, produção de textos, oralidade (escuta e produção oral) e análise linguística/semiótica. As práticas de linguagem são organizadas em campos de atuação, o que reforça a importância da contextualização do conhecimento escolar, "para a ideia de que essas práticas derivam de situações da vida social e, ao mesmo tempo, precisam ser situadas em contextos significativos para os estudantes" (BRASIL, 2017, p. 84). Tais campos são os mesmos nos diferentes níveis de ensino, conforme indicado no quadro 1. Assim, a grande diferença entre as propostas para o ensino fundamental e o médio está, basicamente, no grau de complexidade das práticas de linguagens e dos textos lidos e produzidos. 
Quadro 1: Os campos de atuação das práticas de linguagem na BASE

\begin{tabular}{|l|l|l|}
\hline \multicolumn{1}{|c|}{ ENSINO FUNDAMENTAL } & \multicolumn{1}{c|}{ ENSINO MÉDIO } \\
\hline $\begin{array}{l}\text { Campo da vida } \\
\text { cotidiana }\end{array}$ & \multicolumn{1}{c|}{ ANOS FINAIS } & Campo da vida pessoal \\
\hline $\begin{array}{l}\text { Campo } \\
\text { artístico-literário }\end{array}$ & Campo artístico-literário & Campo artístico-literário \\
\hline $\begin{array}{l}\text { Campo das práticas de } \\
\text { estudo e pesquisa }\end{array}$ & $\begin{array}{l}\text { Campo das práticas de } \\
\text { estudo e pesquisa }\end{array}$ & $\begin{array}{l}\text { Campo das práticas de } \\
\text { estudo e pesquisa }\end{array}$ \\
\hline Campo da vida pública & Campo jornalístico-midiático & Campo jornalístico-midiático \\
\cline { 2 - 3 } & $\begin{array}{l}\text { Campo de atuaçăo na vida } \\
\text { pública }\end{array}$ & $\begin{array}{l}\text { Campo de atuaçăo na vida } \\
\text { pública }\end{array}$ \\
\hline
\end{tabular}

Fonte: BNCC, 2017, p. 501

No que diz respeito à análise linguística, a BNCC reforça a recomendação do tratamento contextualizado de aspectos gramaticais. Quanto à prática de análise linguística no ensino fundamental, por exemplo, recomenda:

estudos de natureza teórica e metalinguística - sobre a língua, sobre a literatura, sobre a norma padrão e outras variedades da língua - não devem nesse nível de ensino ser tomados como um fim em si mesmo, devendo estar envolvidos em práticas de reflexão que permitam aos estudantes ampliarem suas capacidades de uso da língua/linguagens (em leitura e em produção) em práticas situadas de linguagem (BRASIL, 2017, p.71).

Diferentemente dos PCN que são mais genéricos ao abordarem a análise linguística, a BNCC, no tratamento do ensino de língua portuguesa no nível fundamental, distribui os objetos do conhecimento, conforme as habilidades, as práticas e os campos. Há, por vezes, salvo engano, uma concessão à prática há muito criticada de reconhecimento de classes ou mera rotulação das classes (NEVES, 2003). É o que se depreende da habilidade relacionada à morfologia/morfossintaxe, recomendada para o $3^{\circ}$ ano: "(EFo3LPo8) Identificar e diferenciar, em textos, substantivos e verbos e suas funções na oração: agente, ação, objeto da ação" (BRASIL, 2017, p.117). Essa habilidade, se mal compreendida, levará o ensino do substantivo e do verbo a se limitar à sua identificação e seus valores semânticos, quando sabemos que assumem no texto também funções discursivas.

$\mathrm{Na}$ abordagem do ensino de língua portuguesa no ensino médio, o documento adota uma organização mais geral, apresentando habilidades relacionadas a práticas de linguagem, mas sem estabelecer elo direto com objetos do conhecimento. Percebe-se 
claramente a relação dessa seção do documento com a matriz de referência do Enem, tal como se depreende nos PCN. De todo modo, a BNCC mantém a recomendação de um tratamento da análise linguística/semiótica voltada ao uso:

No Ensino Médio, aprofundam-se também a análise e a reflexão sobre a língua, no que diz respeito à contraposição entre uma perspectiva prescritiva única, que segue os moldes da abordagem tradicional da gramática, e a perspectiva de descrição de vários usos da língua.

Ainda que continue em jogo a aprendizagem da norma-padrão, em função de situações e gêneros que a requeiram, outras variedades devem ter espaço e devem ser legitimadas (BRASIL, 2017, p.504).

Para exemplificar o tratamento de temas gramaticais na BNCC, tomemos três tópicos abordados nas três questões objeto de apreciação no questionário aplicado aos professores: emprego do artigo, modo verbal e tempo verbal. O primeiro tópico, tratado na questão 1 do questionário, figura na BNCC em todos os campos de atuação dos $8^{\circ}$ e $9^{\circ}$ anos, na prática de análise linguística/semiótica:

(EFo8LPog) Interpretar efeitos de sentido de modificadores (adjuntos adnominais - artigos definido ou indefinido, adjetivos, expressões adjetivas) em substantivos com função de sujeito ou de complemento verbal, usando-os para enriquecer seus próprios textos (BRASIL, 2017, p.189).

Vê-se que a habilidade não requer a mera classificação dos artigos em definido ou indefinido, mas a interpretação dos efeitos de sentido decorrentes do emprego de modificadores e determinantes, como explora a questão 1 do questionário (ver adiante).

Já o tema modo verbal é focalizado em habilidades dos $6^{\circ}$ e $7^{\circ}$ ano, em todos os campos de atuação, e do Ensino Médio. No $6^{\circ}$ ano, o documento destaca a habilidade de "Analisar a função e as flexões de substantivos e adjetivos e de verbos nos modos Indicativo, Subjuntivo e Imperativo: afirmativo e negativo" e de "Identificar os efeitos de sentido dos modos verbais, considerando o gênero textual e a intenção comunicativa" (BRASIL, 2017, p.171). No Ensino Médio, os modos verbais são considerados em conjunto com outros recursos modalizadores. A questão 2 do questionário aborda modo verbal, mas exige que o aluno estabeleça elo entre o modo e o sentido que supostamente expressa, sem aplicação a nenhuma frase. Trata-se de questão que explora a metalinguagem sem nenhuma contextualização que a justifique. Para além do problema já discutido na literatura de que o indicativo não é o modo da certeza, nem o subjuntivo o modo da dúvida, há o tratamento isolado e estanque do tema. 
Para encerrar esta breve apresentação sobre a BNCC, o tema tempo verbal aparece nas habilidades do $5^{\circ}$ ano, para identificar os valores temporais em tempos verbais do indicativo; no $6^{\circ}, 7^{\circ}$ e $8^{\circ}$ ano para ser utilizado como recurso linguístico na produção escrita; e do $6^{\circ}$ ao $9^{\circ}$ como recurso linguístico na leitura e na análise linguística/semiótica. A questão 3 do questionário que aborda esse tema se limita a que o aluno identifique o tempo verbal predominante. Noutras palavras, o aluno tem de ter domínio da nomenclatura para responder à questão.

\section{Metodologia}

Com o fim de investigar as concepções e as práticas dos professores de língua portuguesa em formação e em atividade em 2019, no que concerne à gramática, realizamos uma pesquisa do tipo survey com abordagem quali-quantitativa. A amostra, selecionada de forma não-probabilística, foi constituída de 171 sujeitos, distribuídos conforme descrito no quadro 1.

Quadro 2: Distribuição dos participantes

\begin{tabular}{|l|l|l|}
\hline Categoria & No & $\%$ \\
\hline Aluno de Letras que não lecionam & 41 & $24 \%$ \\
\hline Alunos de Letras que lecionam & 28 & $16,4 \%$ \\
\hline Aluno de Pedagogia que não lecionam & 6 & $3,5 \%$ \\
\hline Aluno de Pedagogia que lecionam & 13 & $7,6 \%$ \\
\hline Professor em atividade & 83 & $48,5 \%$ \\
\hline TOTAL & 171 & $100 \%$ \\
\hline
\end{tabular}

Fonte: autoria própria

Os dados foram coletados por meio de um questionário online com 3 questões abertas e 9 questões fechadas com a escala Likert de 5 pontos, assim definidos: discordo totalmente - discordo - não sei - concordo - concordo plenamente. Este instrumento foi criado no Google Formulários e disponibilizado em redes sociais em grupos de alunos de Letras e Pedagogia e professores de Língua Portuguesa. O questionário, respondido de forma totalmente anônima, não coletou nenhuma informação pessoal dos participantes os quais foram informados do objetivo da pesquisa e de que, ao clicarem em "enviar", estariam autorizando o uso dos dados da pesquisa.

As categorias de análise foram depreendidas das questões, conforme descrito a seguir. 
A) Noção de gramática: para avaliar até que ponto os conhecimentos linguísticos ampliaram a noção de gramática para além da visão normativa, cumpre saber qual é a noção de gramática predominante no grupo pesquisado. Esta categoria é inferida da resposta à questão 1: A gramática de uma língua tem regras rígidas que devem observadas pelos falantes em qualquer situação.

B) Objetivo do ensino de língua portuguesa e de gramática: ao dar sua opinião sobre o que julga ser o objetivo do ensino, o participante deixa entrever o grau de influência das teorias estudadas e pode mostrar uma distância entre a teoria e a efetiva prática. Como é ponto central da pesquisa, essa categoria se distribui nas questões fechadas 2,3 e $6: 0$ ensino de língua portuguesa deve se restringir apenas à leitura e à produção de textos; $A$ função do ensino de gramática é levar o aluno a escrever melhor e $O$ ensino de gramática nas escolas é inútil para o aluno.

Encontra-se ainda em uma questão semiaberta, reproduzida no quadro 3.

Quadro 3: questão semiaberta sobre ensino de gramática

1. Para que ensinar gramática na escola?

( ) para levar o aluno a escrever melhor.

( ) para levar o aluno a falar e escrever melhor.

( ) para cumprir o programa escolar.

( ) para preparar o aluno para o vestibular.

( ) para dar condições de o aluno usar a língua materna com segurança.

( ) para

Fonte: autoria própria

C) Concepção sobre língua falada: esta variável visa avaliar até que ponto a oralidade, que ganhou seu lugar no ensino de língua desde os PCN, é de fato compreendida pelos professores de língua portuguesa como objeto de ensino, ou se é tida como homogênea, associada ao uso coloquial e informal e, por isso, considerada desnecessária no ensino formal. Associa-se à questão 5: Qualquer usuário de uma dada língua materna domina plenamente a língua falada.

D) Estratégias de ensino de gramática: Igualmente central na pesquisa, esta variável visa captar a opinião de professores sobre a prática de ensino de gramática. Mais uma vez, pode ajudar a estimar a diferença entre a teoria e a prática, em cotejo com outras questões. Foi usada a questão reproduzida no quadro 3. 
Quadro 3: questão semiaberta sobre estratégia de ensino de gramática

2. Como ensinar gramática na escola?

( ) por meio de exercícios de identificação de classes e funções em frases

( ) por meio de exercícios de preenchimento de lacunas em frases, seguindo modelos.

( ) por meio da produção de textos.

( ) por meio de exercícios de identificação de determinados itens gramaticais em textos.

( ) por meio da leitura de gramáticas e resolução de exercícios.

( ) por meio

Fonte: autoria própria

E) Avaliação do curso: esta variável pretende conhecer como os participantes avaliam o curso quanto ao preparo para o exercício da função. Corresponde à questão 4: $\mathrm{O}$ curso de Letras prepara o aluno para o pleno exercício da função de professor.

E) Noção de gramática contextualizada: esta variável corresponde a três questões fechadas. Em cada uma delas, o respondente deveria avaliar, usando a escala Likert, se uma dada questão de gramática representava um bom exemplo de gramática contextualizada. As questões avaliadas estão reproduzidas nas Figuras 1, 2 e 3 a seguir.

Figura 1: questão de gramática 1

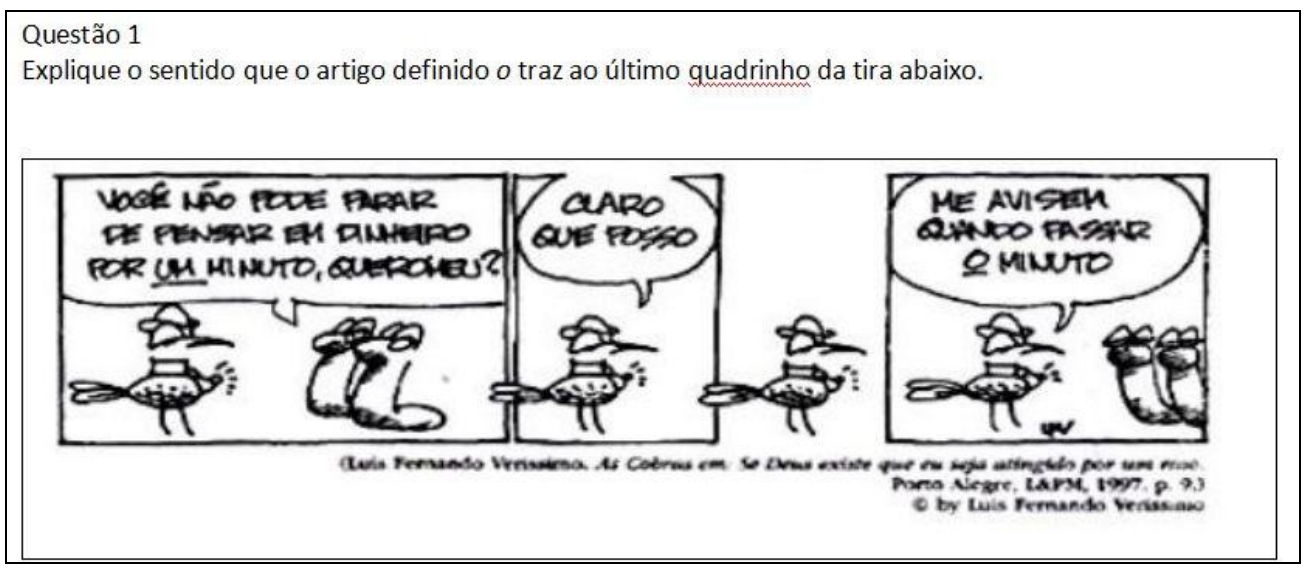

Fonte: DELMANTO, D.; CASTRO, M. C. Português: Idéias \& Linguagens: $5^{\text {a }}$ série. 12. ed. [reformulada]. São Paulo: Saraiva, 20062006, p. 151.

Figura 2: questão de gramática 2

Questão 2

Sobre os modos verbais, está correta a sequência:

I - Modo verbal que expressa ideia de certeza, quando um fato é concluído como real;

II -Modo verbal que expressa dúvida, incerteza, quando há poucas possibilidades de concretização da ação

verbal;

III - Modo verbal que pode estar na forma afirmativa ou na forma negativa. Expressa ideia de ordem, conselho ou pedido.

a) modo imperativo - modo subjuntivo - modo indicativo.

b) modo imperativo - modo indicativo - modo subjuntivo.

c) modo indicativo - modo subjuntivo - modo imperativo.

d) modo indicativo - modo imperativo - modo subjuntivo. 
Fonte:

https://exercicios.mundoeducacao.bol.uol.com.br/exercicios-gramatica/exercicios-sobre-tempos-modosverbais.htm. Acesso 25 jun. 2019.

Figura 3: questão de gramática

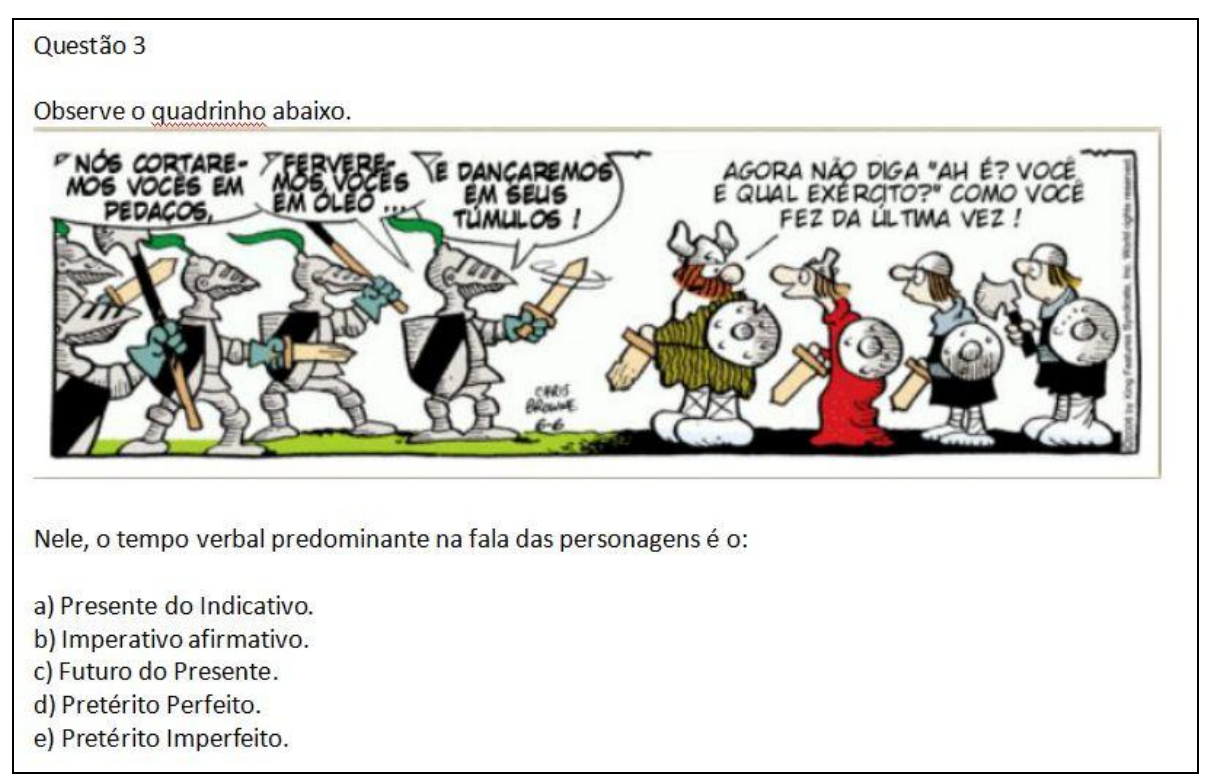

Fonte:

http://veredasdalingua.blogspot.com/2014/12/questoes-com-quadrinhos-10-testes.html. Acesso em 25 jun. 2019.

Após a coleta, os dados foram tabulados no software SPSS, v.16, analisados quantitativamente quanto à frequência e interpretados qualitativamente.

\section{Análise e discussão dos resultados}

Quanto à primeira categoria de análise, os dados mostraram que, embora a grande maioria (59,6\% de discordância e $24,6 \%$ de discordância total) já conceba a gramática como além de um conjunto de regras imutáveis, parte da amostra, 15,8\% (27/171), ainda a concebe como um conjunto de regras que devem ser observadas em qualquer situação.

Isso revela ainda que, a despeito de toda discussão em prol da heterogeneidade linguística e da necessidade de se considerar a situação discursiva na avaliação da linguagem, ainda há professores que adotam uma visão unificadora da língua. De todo modo, o índice de $84,2 \%$ de respostas discordantes indicia uma concepção flexível das regras gramaticais, o que se coaduna com o que recomendam os documentos oficiais e as pesquisas sobre os usos (cf. VIEIRA; BRANDÃO, 2007). 
Quanto ao que pensam ser o objetivo do ensino de língua e de gramática, observamos certas incongruências. A resposta à pergunta sobre se o ensino de língua deve se restringir à leitura e à escrita foi praticamente categórica: 99,4\% (170/171) acreditam que o ensino de língua portuguesa deve ir além da leitura e da escrita.

Essa resposta pode indicar a valorização do ensino de gramática como dissociada das práticas de leitura e de escrita, como afirma Neves (2003), quando comenta a incoerência que se manifestou nas escolas entre o material oferecido para leitura e a análise linguística:

Ficam os textos a documentar a variabilidade e a evolução da língua, e, a seu lado, as lições gramaticais a desconhecer variação e mudança, e desconhecer principalmente, a ampla faixa de liberdade que o falante tem, no uso da língua, para compor seus enunciados" (NEVES, 2003, p.69).

Naturalmente, o instrumento não permitiu captar toda a complexidade da questão, o que exigiria complementação da pesquisa com outras técnicas, como o grupo focal, o que ficará para um segundo momento desta pesquisa.

De todo modo, essa interpretação é reforçada pelo alto índice de respostas sobre a utilidade do ensino de gramática nas escolas: 93\% (159/171) acham que o ensino de gramática nas escolas é útil ao aluno. Para os participantes, o ensino de gramática nas escolas deve servir, em primeiro lugar, para dar condições ao aluno de usar a língua materna com segurança; e, em segundo lugar, para levar o aluno a falar e a escrever melhor (42\%). Parece, assim, que, a julgar pela resposta que apresentou segundo maior percentual, permanece a noção de gramática como norma, como ideal linguístico a ser atingido para "falar e escrever melhor".

Reconhecemos o papel do ensino de uma gramática "não desvinculada dos processos de constituição dos enunciados" (NEVES, 2003, p.22), portanto, ligada aos usos, o que naturalmente inclui a fala. Igualmente não desconsideramos a importância do ensino de gramática para permitir à criança "entrar equilibradamente na posse de conhecimentos que Ihe possibilitarão adequação sociocultural de enunciados" (NEVES, 2003, p.25). O problema dessa afirmação é o juízo de valor contido no emprego do termo "melhor", que pressupõe um julgamento dos fatos linguísticos como simplesmente certos ou errados, conforme determina a norma gramatical, estabelecida por valoração social, sem levar-se em conta o fator da adequação social. Trata-se do que Neves (2003, p.22) considera uma das maiores aberrações no tratamento da linguagem pela escola. 
Revelam ainda uma visão de ensino de gramática como um ensino exclusivo da norma gramatical algumas afirmações ${ }^{1}$ inclusas na pergunta semiaberta, que estão transcritas em (01-05).

(01) "Para fazer o aluno a compreender e aplicar as regras".

(02) "Para que o aluno aprenda a escrever correto, pq escrever melhor é parte criativa, e não depende da gramática".

(03) "Para uso em situação formal".

(04) "Tomado o significado de gramática, como aquela referente à norma culta, isto é, as nomas linguísticas impostas pelas classes sociais dominantes, o ensino de gramática serve para ensinar como ler e escrever textos que seguem tais parâmetros".

(05) "para o alunos ter condições de saber o que é a gramática".

Tais respostas mostram que a noção de gramática como conjunto de regras, embora não pareça predominante, ainda permanece, como se vê pelas afirmações (01) e (03). Revelam ainda a concepção de que apenas a língua escrita deve obedecer à norma padrão, como indicam as afirmações (02) e (04), e de que ensinar algo deve ser ensinar o conceito, como afirma-se em (05). Cumpre lembrar que essa confusão entre aprender a usar e aprender o conceito está presente nas inúmeras atividades de identificação e rotulação de entidades linguísticas, bastante comuns na escola, e nas questões avaliadas pelos participantes desta pesquisa.

Já quanto à concepção de língua falada, os resultados indicam que, para a maioria dos participantes, $64,3 \%$ (110/171), nem todo usuário de uma dada língua materna domina plenamente a língua falada, o que condiz com a necessidade, apontada nos documentos oficiais, de a escola incluir no ensino de língua materna atividades que levem o aluno a desenvolver suas habilidades no uso da oralidade (BRASIL, 2018, p.78-80). Também nesta variável, encontramos um terço dos participantes (57/171) que pensa que todo usuário de uma dada língua domina a língua falada, tornando, assim, desnecessário o tratamento escolar da língua falada. Ainda que baixo, chama a atenção o índice de 11,6\% (20/171) de participantes que responderam que o ensino de gramática na escola serve para "para levar o aluno a escrever melhor", o que indicia uma concepção de língua falada dissociada da gramática, entendida, provavelmente como norma, a qual estaria ligada apenas à língua

\footnotetext{
${ }^{1}$ As respostas foram transcritas tal qual estão no formulário, sem edição.
} 
escrita, considerada mais formal que a falada. Essa visão revela a atitude sobre que fala Neves (2003, p.93) de permitir certos usos apenas na língua falada, "como se ela fosse uma modalidade menor, de situações de interação inferiores, nas quais tudo vale (mais uma vez incorrendo-se no erro de dicotomizar modalidades)".

Quanto à avaliação do curso de graduação, a maioria, 67,3\% (115/171), acredita que o curso não prepara para o exercício do magistério. Não houve significativa diferença entre os cursos, como pode ser visto na tabela 1 a seguir.

Tabela 1: avaliação do curso pelos participantes

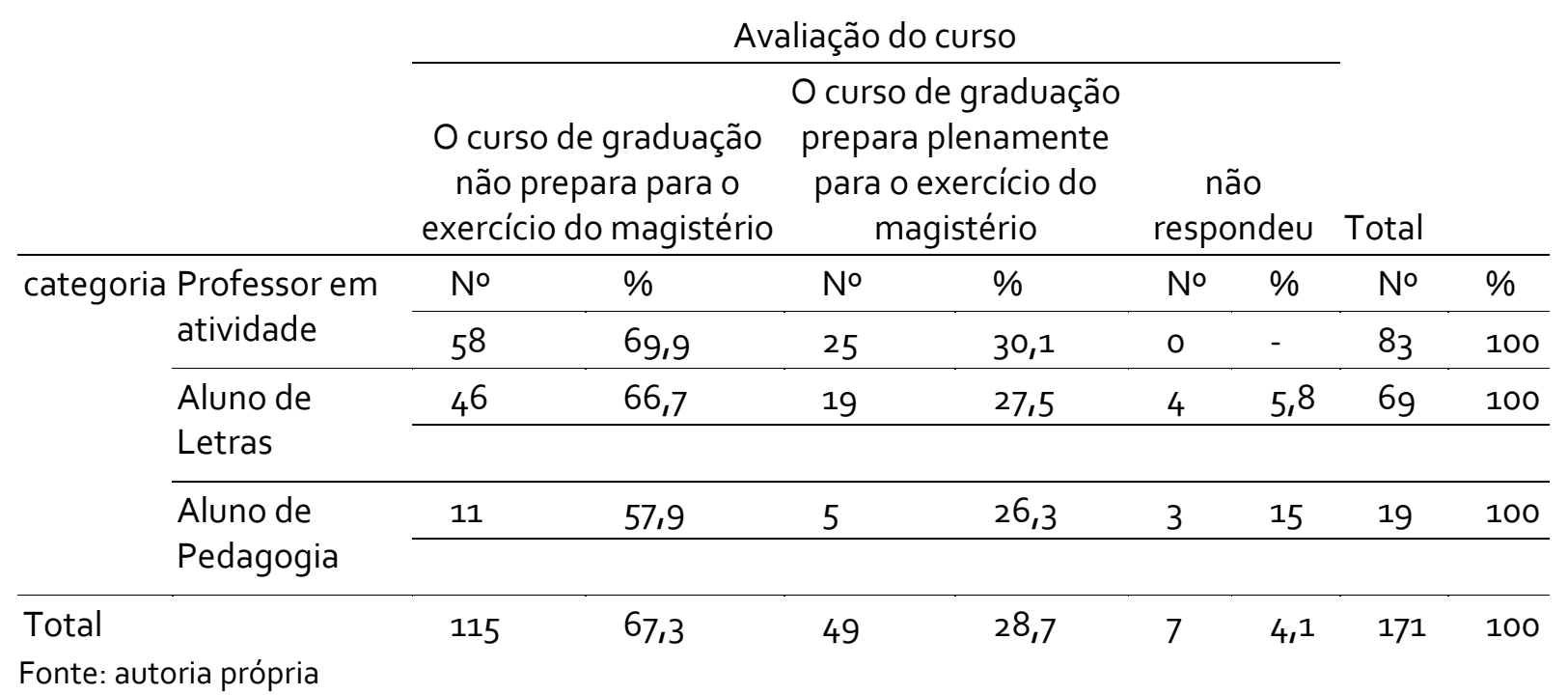

Quanto às estratégias de ensino de gramática, 71,3\% das respostas incluíram como estratégia a prática de produção e revisão de textos (122/171), o que está em conformidade com as recomendações dos PCN:

Um dos aspectos fundamentais da prática de análise lingüística é a refacção dos textos produzidos pelos alunos. Tomando como ponto de partida o texto produzido pelo aluno, o professor pode trabalhar tanto os aspectos relacionados às características estruturais dos diversos tipos textuais como também os aspectos gramaticais que possam instrumentalizar o aluno no domínio da modalidade escrita da língua (BRASIL, 1998, p.80).

É o que se depreende claramente das respostas inclusas na parte aberta do formulário, algumas das quais estão transcritas em (06) -(10).

(o6) A partir do texto, trazendo o aluno a refletir sobre as regras internas da língua e que atuam em forma de discurso

(07) Através de aulas que combinem exposição e práticas de leitura e escrita de diversos gêneros discursivos, em especial, aqueles que fazem parte da realidade social do aprendiz. 
(o8) Através de textos, que levem o aluno a refletir sobre determinados usos.

(og) O ensino de gramática deve levar o aluno a entender o funcionamento da língua em uso e de acordo c as finalidades de comunicação e sentidos a serem produzidos.

(10) Por meio da análise de itens gramaticais presentes em textos de modo a verificar de que maneira contribuem para a construção dos sentidos e para o cumprimento de certos propósitos comunicativos.

Exemplo de abordagem condizente com essas propostas é a questão 1 do formulário de pesquisa (ver metodologia), que foi avaliada como um bom exemplo de questão contextualizada por 80,1\% (116 de concordância e 21 de concordância plena, totalizando 137/171). Essa questão explora o uso do artigo definido em uma tirinha, não se limitando à mera identificação e classificação, mas recorrendo ao seu sentido no contexto em que se opõe ao artigo indefinido também empregado na tirinha. Apenas 11,1\% (19/171) discordaram e 8,8\% (15/171) não souberam responder.

Curiosamente, $71,3 \%$ (122/171) incluíram de uma até quatro das opções que indiciam uma proposta de ensino de gramática descontextualizado: exercícios de identificação de determinados itens gramaticais em textos (53,2\% - 91/171); por meio da leitura de gramáticas e resolução de exercícios (32,7\% - 56/171); exercícios de identificação de classes e funções em frases (29,8\% - 51/171); exercícios de preenchimento de lacunas em frase (13,4\% - 23/171), seguindo modelos.

Note-se que a primeira estratégia, inclusa em mais da metade das respostas, propõe a identificação de itens gramaticais em textos, o que tem sido chamado desde Lajolo (1982; 2009) de se usar o texto como pretexto para ensino de questões gramaticais. Essa incompreensão do que significa ensinar gramática contextualizada é tão comum que, na ânsia de atender às demandas da modernidade, oferecendo um ensino contextualizado com textos variados e multimodais, os professores costumam recorrer a textos como tirinhas, memes e charges, como se a simples presença desses textos em um exercício garantisse que as questões de gramática fossem contextualizadas (cf. MAROUN, 2006; PRADO, 2016).

Exemplo deste tipo de abordagem é a questão 3 (ver metodologia) do formulário de pesquisa, que 63,3\% (9o de concordância e 18 de concordância plena, totalizando 108/171) consideraram um bom exemplo de questão de gramática contextualizada, como mostra o 
gráfico 1. Apenas 27,5\% (47/171) discordaram dessa análise e 9,4\% (16/171) não souberam avaliar, o que mostra a insegurança neste aspecto.

Gráfico 1: Avaliação da questão 3 como exemplo de gramática contextualizada

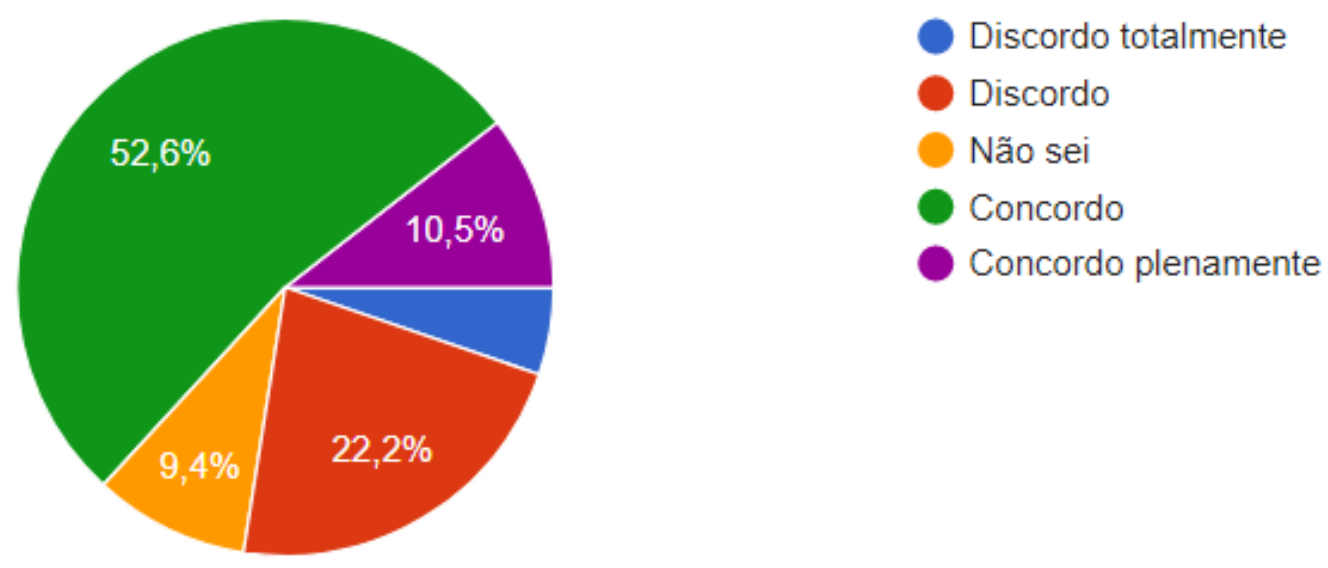

Fonte: autoria própria

Se a maioria dos participantes avaliaram as questões 1 e 3 como bons exemplos de uma abordagem de gramática contextualizada, não pensaram assim ao avaliar a questão 2, pois $66,7 \%$ (114/171) a consideraram questão de gramática descontextualizada, conforme ilustrado na tabela 2.

Tabela 2: Avaliação da questão 2 como exemplo de gramática contextualizada

\begin{tabular}{l|r|r|}
\hline & No & \multicolumn{1}{|c|}{$\%$} \\
\hline Concordo & 38 & 22,2 \\
Concordo plenamente & 5 & 2,9 \\
Discordo & 75 & 43,9 \\
Discordo totalmente & 39 & 22,8 \\
Não sei & 14 & 8,2 \\
Total & 171 & 100,0 \\
\hline
\end{tabular}

Fonte: autoria própria

Provavelmente isso se deveu ao fato de a questão 2 não trazer texto nem mesmo recorrer a frases, mas simplesmente exigir o conhecimento de nomenclatura e conceitos gramaticais. Todavia, a questão se enquadra nas propostas que tiveram boa adesão dos 
participantes, como a que propôs que o ensino de gramática se desse por meio da leitura de gramáticas e resolução de exercícios (32,7\% - 56/171), o que evidencia um certo abismo entre teoria e prática.

Esse abismo é bem ilustrado ao se compararem os resultados encontrados até aqui e as respostas abertas e opcionais ao item do formulário que solicitava que o participante copiasse um exemplo de questão de gramática que aplicou ou aplicaria aos seus alunos. Tivemos 81 respostas, das quais 67 foram consideradas válidas na análise, após a retirada de 14 respostas por serem extremamente vagas como "usar uma", "textos", "me passa a manteiga" ou por conterem uma justificativa da não apresentação, como "não possuo", "nunca apliquei", "não sei", "Me recordo apenas dos exercícios realizados nos livros de gramática". Dessas 67, 27 foram exemplos de questões calcadas na mera identificação, 2 apontaram a questão 2 do formulário e 1 apontou a questão 3 como exemplos de questão que aplicariam. Portanto, $44,7 \%$ (30/67) dos participantes que responderam a este item parecem praticar um ensino de gramática descontextualizada, como indicam alguns dos exercícios propostos transcritos a seguir.

(11) 1. Identifique os pronomes presentes na tirinha. 2. Classifique os pronomes identificados na questão 1.

(12) Dê exemplos de diferentes tipos de sujeito com seus respectivos predicados.

(13) Após exposição e revisão do conteúdo, o aluno identificará os verbos em várias frases.

O que estes dados mostram é que os resultados a que chegou Neves (1990), em pesquisa de campo com 170 professores do ensino fundamental, antes da publicação dos PCN e da BNCC, portanto, parecem se repetir na presente pesquisa:

O que verifiquei (NEVES, 1990a) é que os professores foram despertados para uma crítica dos valores da gramática tradicional, e, por isso, têm procurado dar aulas de gramática não-normativa, o que os leva a que as aulas de gramática sejam reduzidas a uma simples exposição de taxonomia (NEVES, 2003, p.114).

De fato, a gramática propriamente prescritiva figura pouco nas propostas. Apenas 5 dos exercícios propostos, transcritos em (18)-(20), exploram aspectos normativos.

(14) Corrija as sentenças, retiradas de redações dissertativas, quando necessário: a) Os problemas da população é a saúde, educação e segurança. etc. 
(15) Escrever sobre um cotidiano familiar, depois verificar como o aluno usa a língua escrita e por último trabalhar as palavras de acordo com a norma padrão. Alunos do $4^{\circ}$ ano do fundamental I

(16) Identificação da forma de escrita da palavra, ex: mortandela ou mortadela? Respeitando a variação linguística.

(17) Trabalhar a pontuação utilizando textos como carta.

(18) Regência nominal e verbal.

Esse tratamento da gramática limitada à metalinguagem é não apenas improdutivo, porque não leva ao desenvolvimento da competência comunicativa do aluno, mas também, como afirma Neves (2003), é "contraproducente, porque leva a uma descrença final sobre a validade da investigação gramatical" (NEVES, 2003, p, 125). A autora assevera que a abordagem escolar da gramática não pode alhear-se do real funcionamento da linguagem, sob pena de perder toda sua legitimidade.

Levar o aluno a atentar para o real funcionamento da linguagem, como também recomendam os documentos oficiais, é o que pretendem alguns dos exercícios propostos pelos participantes: 7 apresentaram como exemplo de questão o teste de $\mathrm{Cloze}^{2}$ para explorar aspectos gramaticais, 12 sugeriram atividades de análise a partir da leitura e produção de textos e 2 citaram a questão 1 como exemplo de questão que aplicaria, totalizando 31,3\% (21/67), como vemos em (19)-(22).

(19) Atividade "cloze" para preenchimento dos tempos verbais de uma crônica e assim perceber umas das características centrais desse gênero discursivo.

(20) Entrega de Produções Textuais escritas pelos alunos para que observem os aspectos mencionados, geralmente coloco na lousa o que devem observar ou faço uma tabela na folha e eles marcam o que encontrou no texto. Depois reescrevem.

(21) Perceber os efeitos de sentido provocados pela escolha dos substantivos em capas de jornal sobre o "7x1 do mundial masculino Brasil x Alemanha"

(22) Um exercício de produção do gênero $M E M E$, através da observação do gênero em rede social e mapeamento das estratégias gramaticais mais recorrentes no gênero.

Por fim, resta um breve comentário sobre a opção pela resposta neutra da escala Likert do formulário. Esta resposta, em que o participante não assume o compromisso de

\footnotetext{
2 Técnica em que se omitem todas as quintas palavras de um texto que são substituídas por um traço.
} 
expressar sua opinião, visa deixar o participante à vontade para responder questões obrigatórias. Houve, no total, 35\% de respostas neutras. Como mostra a tabela 3, o índice de abstenção foi maior na avaliação das questões, que, de certo modo, está mais relacionada à prática que as demais questões de cunho mais teórico e mostra maior insegurança por parte dos respondentes.

Tabela 3: Índice de respostas neutras

\begin{tabular}{lllll}
\hline Questão & Tema & N & $\begin{array}{l}\% \text { de respostas } \\
\text { neutras }\end{array}$ & $\begin{array}{l}\% \text { do } \\
\text { total }\end{array}$ \\
\hline 01 & Noção de gramática & 0 & $0 \%$ & $0 \%$ \\
\hline 02 & Objetivo do ensino de língua portuguesa & 0 & $0 \%$ & $0 \%$ \\
\hline 03 & Objetivo do ensino de gramática & 5 & $8,3 \%$ & $2,9 \%$ \\
\hline 04 & Avaliação do curso & 6 & $10 \%$ & $3,5 \%$ \\
\hline 05 & Concepção de língua falada & 4 & $6,7 \%$ & $2,5 \%$ \\
\hline 06 & Utilidade do ensino de gramática & 0 & $0 \%$ & $0 \%$ \\
\hline 10 & Avaliação da questão 1 & 15 & $25 \%$ & $8,8 \%$ \\
\hline 11 & Avaliação da questão 1 & 14 & $23,3 \%$ & $8,2 \%$ \\
\hline 12 & Avaliação da questão 1 & 16 & $26,7 \%$ & $9,4 \%$ \\
\hline TOTAL & & 60 & $100 \%$ & $35 \%$ \\
\hline
\end{tabular}

Fonte: autoria própria

\section{Considerações finais}

Com o fim de avaliar se a prática de ensino de gramática nas escolas alcançou a desejada integração texto/gramática, conforme recomendam os documentos oficiais, há mais de vinte anos, empreendemos uma pesquisa survey com 171 professores em atividade e em formação.

Os resultados mostraram que: (1) não há significativa diferença entre as opiniões dos professores em formação e dos professores em atividade em todas as questões, indicando um grupo relativamente homogêneo quanto aos temas abordados. (2) os respondentes mostraram-se seguros ao responder sobre a noção de gramática, a utilidade do ensino de gramática e o objetivo do ensino de língua portuguesa. Quanto a este, o resultado foi quase categórico: 99,4\% consideram que o ensino de língua portuguesa deve ir além da leitura e da escrita. (3) Embora a maioria (84,2\%) reconheça a flexibilidade das regras gramaticais, ainda apresenta uma visão de ensino de gramática pautado na norma, "para fazer o aluno compreender e aplicar regras".

Os dados evidenciaram ainda uma discrepância entre a teoria que os participantes aprenderam nos cursos de formação e a prática em sala de aula, exercida ou planejada. Se, 
por um lado, a maioria $(64,3 \%)$ admite que nem todo usuário de uma dada língua domina plenamente a língua falada, por outro, essa mesma maioria restringe o ensino de gramática a práticas ligadas à língua escrita, como se a primeira fosse desprovida de norma. De um lado, a maioria dos participantes $(71,3 \%)$ concebem a importância de um ensino de gramática vinculado à prática de produção e revisão de texto; de outro, demonstram ainda

ter dificuldade de elaborar atividades que expressem essa integração, uma vez que sugeriram questões de mera identificação e classificação de entidades gramaticais e avaliaram como contextualizada uma questão que usa uma tirinha como pretexto para a classificação do tempo verbal.

Ainda que esta pesquisa apresente limitações, como a ausência de poucas perguntas abertas que permitissem captar de forma mais subjetiva as opiniões dos respondentes; a coleta de dados apenas por formulário, quando a formação de um grupo focal permitiria uma discussão mais ampla das questões abordadas; a amostra aleatória não probabilística que não permitiu um equilíbrio entre as categorias de participantes, consideramos que a análise empreendida contribuiu para apresentar um quadro geral das opiniões e atitudes dos professores de língua portuguesa quanto ao ensino de gramática. E, por não se limitar a professores em atividade, mas incluir professores em formação, a pesquisa foi útil para apontar a necessidade de reformulação dos cursos de formação de professores de língua seja na grade curricular, incluindo disciplinas que deem conta de um ensino produtivo para além das disciplinas teóricas, seja na revisão das disciplinas já existentes, incluindo unidades de aplicação dos conteúdos teóricos.

\section{Referências}

ALVES, R. F. O ensino de gramática no cenário atual: impactos de princípios e parâmetros ao longo de três décadas. Revista Linguagem \& Ensino. Pelotas, v. 20, n.2, p. 277-307, 2017. Disponível em: <http://revistas.ucpel.edu.br/index.php/rle/article/viewFile/1709/1089>. Acesso em 30 jun. 2019.

ARAÚJO, M. D. M. de; SOUSA FILHO, S.M. de; LIMA, L. M. de. Espelho, espelho meu: concepções de linguagem e ensino de gramático/análise linguística no ensino médio. Revista Percursos Linguísticos. Vitória, v.8, n.18, p. 272-291, 2018. Disponível em: <http://periodicos.ufes.br/percursos/article/view/19217/13915>. Acesso em 30 jun. 2019.

BRASIL, Ministério da Educação e Desporto. Parâmetros Curriculares Nacionais. $3^{\circ}$ e $4^{\circ}$ ciclos do ensino fundamental. Brasilia: SEF, 1998. 
BRASIL. Ministério da Educação. Secretaria de Educação Média e Tecnológica. Parâmetros curriculares nacionais: ensino médio. Língua Portuguesa. Brasília: MEC/SEMTEC, 2000.

BRASIL. Base Nacional Comum Curricular. Documento homologado pela Portaria $\mathrm{n}^{\circ} 1.570$, publicada no D.O.U. de 21/12/2017, Seção 1, Pág. 146. Brasília, 21 de dezembro de 2017.Disponível em:

<http://basenacionalcomum.mec.gov.br/images/BNCC_EI_EF_110518_versaofinal_site.pdf $>$. Acesso em 28 jun. 2019.

DUTRA, Camilla Maria Martins; RÉGIS, Laura Dourado Loula. Análise linguística em substituição ao ensino de gramática? Incompreensões teórico-metodológicas e possibilidades de articulação dos eixos de ensino. Entrepalavras, [S.I.], v. 7, n. 2, p. 534-551, nov. 2017. ISSN 2237-6321. Disponível em:

<http://www.entrepalavras.ufc.br/revista/index.php/Revista/article/view/969>. Acesso em 29 jun. 2019. doi:http://dx.doi.org/10.22168/2237-6321.7.7.2.534-551.

GERALDI, J. W. Concepções de linguagem e ensino de português. In: O texto na sala de aula. Cascavel: Assoeste, 1984.

LAJOLO, M. P. O texto não é pretexto. Será que não é mesmo? In: Regina Zilberman; Tania Rosing. (Org.). Escola e Leitura: Velha crise - Novas alternativas. 1ed.São Paulo: Global, 2009, v., p. 99-112.

LAJOLO, M. P.; AUTORES, V. O texto não é pretexto. In: Regina Zilberman. (Org.). Leitura em crise na escola: as alternativas do professor. Porto Alegre: Mercado Aberto, 1982, v. , p. 51-62.

MAROUN, Cristiane Ribeiro Gomes Bou. A multimodalidade textual no livro didático de português. 2006. 118 f. Dissertação. Universidade de Brasília. Programa de PósGraduação em Linguística. Mestrado em Linguística. Disponível em:

<http://repositorio.unb.br/bitstream/10482/8854/1/2006_CristianeRibeiroGomesBouMarou n.pdf>. Acesso em 28 jun. 2019.

NASCIMENTO, I. M. Abordagem da gramática nos livros didáticos de língua portuguesa: os parâmetros curriculares nacionais promoveram mudanças? 2018. 142 f. Dissertação (Mestrado em Letras e Linguística) - Universidade Federal de Goiás, Goiânia, 2018.

Disponível em: <https://repositorio.bc.ufg.br/tede/handle/tede/goo6>. Acesso em 30 jun. 2019.

NEVES, M. H. M. A gramática na escola. São Paulo: Contexto, 1990.

NEVES. M. H. M. Que gramática estudar na escola? Norma e uso na Língua Portuguesa. São Paulo: Contexto, 2003.

PRADO, A. da S. A presença do texto multimodal no livro didático: o texto como pretexto a uma análise linguístico-visual. 2016. 58 f. Monografia (Graduação em Letras). 
Departamento Acadêmico de Linguagem e Comunicação e Departamento de Letras Estrangeiras Modernas. Universidade Tecnológica Federal do Paraná. Curitiba, 2016.

POSSENTI, S. Por que (não) ensinar gramática na escola. Campinas: Mercado de Letras, 1996.

TRAVAGLIA, L. C. Gramática e interação: uma proposta para o ensino de gramática no $\mathbf{1}^{\circ}$ e $\mathbf{2}^{\circ}$ graus. São Paulo: Cortez, 1996.

VIEIRA, S.R.; BRANDÃO, S.F. (Orgs.). Ensino de Gramática: descrição e uso. São Paulo: Contexto, 2007.

\footnotetext{
' Maria Claudete Lima, professora Associada da Universidade Federal do Ceará, onde atua na graduação em Letras e no Mestrado Profissional em Letras. Doutora em Linguística pela UFC.

Email: claudete@letras.ufc.br

ii Camila Stephane Cardoso Sousa, professora Adjunta do Departamento de Letras Vernáculas da Universidade Federal do Ceará. Interessa-se pelos estudos de Aquisição e desenvolvimento da linguagem, pela perspectiva sistêmico-funcional, pelo modelo de análise da Avaliatividade e pelos estudos sobre oralidade.

E-mail: camilacardoso@ufc.br

iii Ana Célia Clementino Moura, professora Titular-Livre do Departamento de Letras Vernáculas da UFC. Doutora em Educação pela UFC e pós-doutora em Estudos da Linguagem pela UFU. Seus interesses de pesquisas englobam alfabetização, aprendizagem da língua escrita, produção de texto e avaliação.

E-mail: acmoura27@gmail.com
}

\section{RECEBIDO EM: 07/06/2019 \\ ACEITO EM: 12/08/2019}

